\title{
A New Species of Genus Coeloplana (Ctenophora: Tentaculata: Platyctenida) from Korea
}

\author{
Jun-Im Song* and Sung-Jin Hwang \\ Department of Life Sciences, Ewha Womans University, Seoul 120-750, Korea
}

\begin{abstract}
Since November, 2006, the new creeping platyctenid ctenophore, Coeloplana anthostella n. sp., has been collected from twigs and polyp masses of encrusting dendronephthyans at a depth of 26-32 m off the coast of Munseom, Jejudo Island. This new species is distinguished from C. bocki Komai, 1920 and C. komai Utinomi, 1963 by its smaller size, the absence of dorsal papillae, and the deep scarlet colored star-shaped markings on the dorsal plane. This novel addition to ctenophore fauna is presently described and illustrated in detail.
\end{abstract}

Keywords: taxonomy, Coeloplana anthostella n. sp., Ctenophora, Korea

\section{INTRODUCTION}

The members of the family Coeloplanidae including creeping, floating or swimming ctenophores are greatly compressed in their oral-aboral axis. Especially, the oral portion of the stomodaeum is permanently or temporarily everted to form a creeping sole. Also, comb rows are absent in adults except for the embryo stages (Harbison and Madin, 1982). In 1982, the genera Coeloplana and Vallicula were included to the Coeloplanidae because of the separation of sessile group, genus Lyrocteis of family Lyroctenidae (Mills, 1998). There has been only one sessile platyctenid ctenophore, Lyrocteis imperatoris, described in Korean waters (Song and Hwang, 2009). The creeping ctenophore, Coeloplana anthostella $\mathrm{n}$. sp., which is specifically associated with encrusting dendronephthyans, has been newly added to the ctenophore fauna. The purpose of this study is to clarify the constituent fauna and distribution of ctenophores in Korean waters.

\section{MATERIALS AND METHODS}

The specimens were collected from a depth of $25-32 \mathrm{~m}$ at Munseom $\left(126^{\circ} 32^{\prime} 225^{\prime \prime}\right.$ E, $\left.33^{\circ} 14^{\prime} 189^{\prime \prime} \mathrm{N}\right)$, offshore of Seogwipo, Jejudo Island by SCUBA diving all year round since November 2006. The creeping animals with an undulating margin were attached firmly to the twigs and polyp masses of encrusting dendronephthyans by a flat oral plane (Fig. 1A and $\mathrm{B})$. For the identification, their taxonomic characters

\footnotetext{
*To whom correspondence should be addressed

Tel: 82-2-3277-2364, Fax: 82-2-3277-2385
}

E-mail: jisong@ewha.ac.kr parts were observed using a Stemi SV-6 stereomicroscope (Zeiss) and a model BH2 light microscope (Olympus), and were measured with an ocular micrometer before anesthesia with $\mathrm{MgCl}_{2}$ solution and fixation in $5 \%$ neutral formalin. Internal characteristics were observed in serial sections acquired using a Reichert-Jung microtome. The holotype and most of paratypes are deposited in the Natural History Museum (EWNHM) and some of the paratypes are stocked in the Korean Coral Resource Bank (KCRB), Ewha Womans University.

\section{SYSTEMATIC ACCOUNTS}

Phylum Ctenophora Eschscholtz, 1829

Class Tentaculata Eschscholtz, 1825

Subclass Typhlocoela Ospovat, 1985

Order Platyctenida Bourne, 1900

(=Coeloplanidea Stechow, 1922)

Aberrant ctenophores, compressed in oral-aboral plane to flattened form with two tentacles and sheaths. Comb rows absent in adults.

\footnotetext{
${ }^{1 *}$ Family Coeloplanidae Willey, 1896
}

Family including genera Coelaplana and Vallicula. Adults lacking comb rows, which presented in larvae. An aboral sense organ present. Tentacles having one side branches, enclosed in sheaths. Meridional canals branched and anastomosing. Tentacular canals bifid. Gonads on canals, with externally opening spermatoducts, and with oviducts opening into

\footnotetext{
$1 *$ 납작빗해파리과 (신칭)
} 

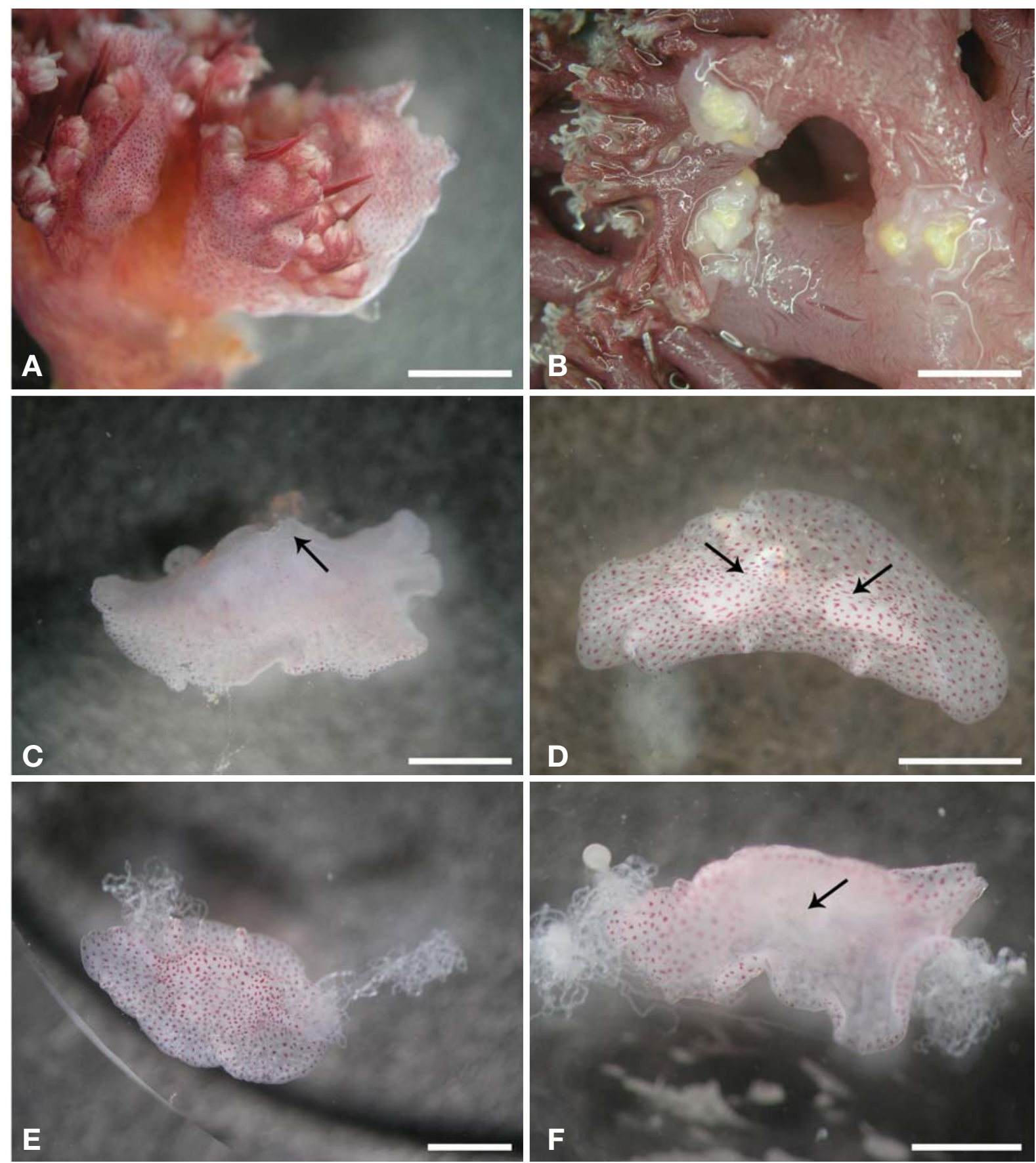

Fig. 1. Coeloplana anthostella n. sp., A, living individuals attached on Dendronephthya spinulosa; $B$, three decolorized specimens in fixation; C-E, dorsal side, $C$, showing hump-like elevation $(\rightarrow)$; $D$, showing two tentacle bases $(\rightarrow)$; $E$, showing two extended tentacles; F, ventral side showing a mouth $(\rightarrow)$. Scale bars $=2 \mathrm{~mm}(A, B), 1 \mathrm{~mm}(C-F)$.

gastrovascular system.

$1 *$ Genus Coeloplana Kowalevsky, 1880

Pharynx permanently everted and flattened. Aboral papillae present in general. As hermaphrodite, young embryos brooded. Species of Coeloplana associated with benthic organisms, creep, float, or swim.

\footnotetext{
1*납작빗해파리속(신칭)
} 

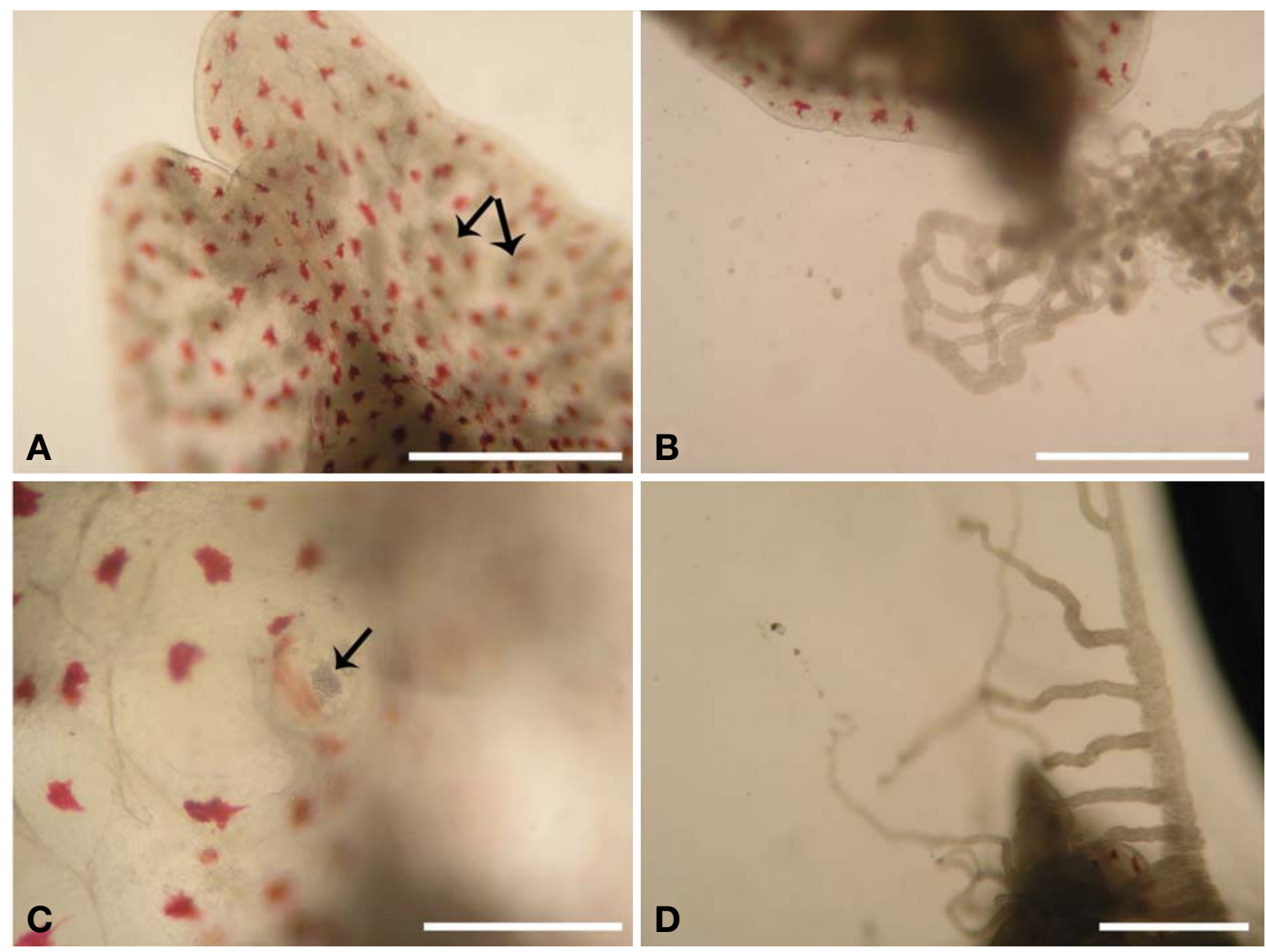

Fig. 2. Coeloplana anthostella n. sp., A, opening of tentacle sheath (TS) and canals (C) $(\rightarrow)$; $B$, one tentacle expelled from TS; C, aboral sense organ $(S)$ with statocyst $(\rightarrow)$; $D$, pinnate tentacle with one side branches. Scale bars=0.5 mm (A-D).

\section{${ }^{1 *}$ Coeloplana anthostella $\mathbf{n}$. sp. (Figs. 1-3)}

Material examined. Holotype: 1 individual attached on twigs and polyp masses of D. spinulosa in alcohol, Munseom, Aug. 16, 2009 (BI Kim), 25-30 m deep by SCUBA, EWNHM 60311. Paratypes: 2 inds. in alcohol, Munseom, Nov. 20, 2006 (SJ Hwang), EWNHM60312; 3 inds. in alcohol, Munseom, Nov. 30, 2006 (SJ Hwang), EWNHM60313; 7 inds. in formalin, Munseom, Nov. 28, 2008 (SJ Hwang), EWNHM 60314; 7 inds. in formalin, Munseom, Dec. 26, 2008 (SJ Hwang), EWNHM60315; many inds. in formalin, Munseom, Jan. 11, 2009 (SJ Hwang), EWNHM60316; many inds. in formalin, Munseom, Feb. 8, 2009 (SJ Hwang), EWNHM 60317; many inds. in alcohol, Munseom, Aug. 16, 2009 (BI Kim), EWNHM60318, attached on Dendronephthya spinulosa and other umbellate dendronephthyans $26-32 \mathrm{~m}$ deep by SCUBA.

Description. Creeping flattened ctenophore represents some- what hump-like elevation in its central parts of broad and thin basal expansion (Fig. 1C). Oval shape with undulating margin, $0.88 \times 0.53-3.50 \times 2.88(1.99 \pm 0.87 \times 1.38 \pm 0.55$, $\mathrm{n}=31) \mathrm{mm}$ (tentacular axis $\times$ sagittal axis, length $\times$ width) (Fig. 1C,D).

Two pinnate tentacles having colloblasts in their surface with one side branches (Fig. 2B, D) entirely retracted into each tentacle sheath at both ends of tentacular axis (Fig. 1E, F, Fig. 2A, B). Tip of tentacles globular $(0.04 \times 0.04 \mathrm{~mm}$ in dia.), their side and main branches slender, $0.03 \mathrm{~mm}$ and $0.07 \mathrm{~mm}$ in dia. respectively (Fig. 2B, D). Tentacle sheath flask-shaped in aboral view and two tentacle bases separated each other at aboral pole (Fig. 1D). Under stereomicroscope, ramification of gastrovascular system not clearly visible (Fig. 1A-F). However, each red star-shaped marking situated in pattern at each mesh consisting of thin reticulated gastrovascular canals (Fig. 2A, C).

On aboral pole, polar plate not visible, but a little raised

\footnotetext{
1 *꽃별납작빗해파리 (신칭)
} 

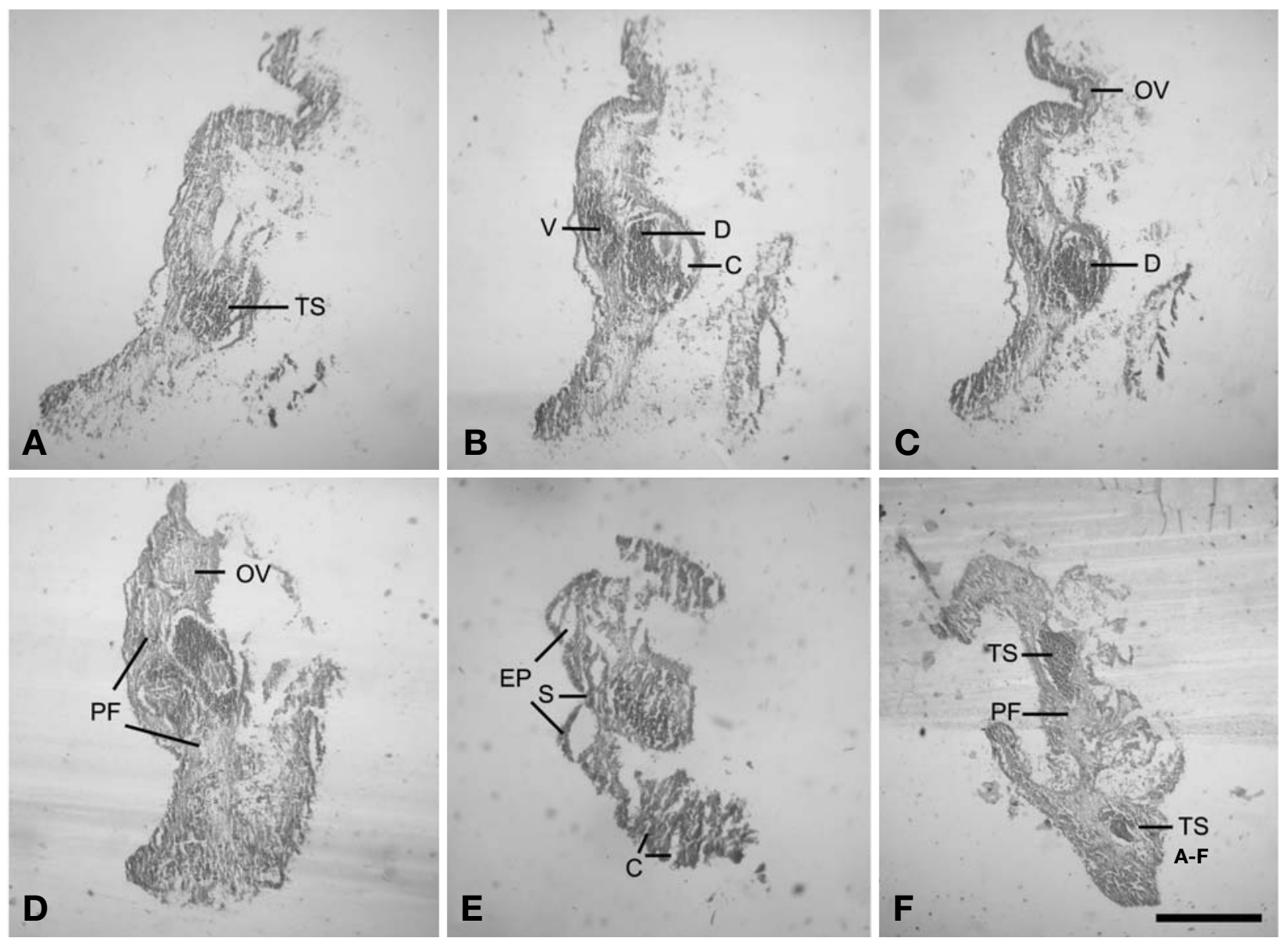

Fig. 3. Coeloplana anthostella n. Sp., A-E, sagittal plane, A, through distal part of TS; B, through proximal part of TS showing dorsal compartment (D) of TS and ventral compartment (V) of TS; $C$, through aboral side of $B$; $D$, through aboral side of $C$ showing ovaries (OV) and pharyngeal folds (PF) at both sides of TS.; E, through aboral pole showing S, excretory pores (EP) and C; F, transverse section of body showing both TS at both sides of inner portion of PF. Scale bars $=0.05 \mathrm{~mm}(A-F)$.

Table 1. Comparison of diagnostic characters of Coeloplana anthostella n. sp. and its related species

\begin{tabular}{|c|c|c|c|}
\hline Characters & C. anthostella n. sp. & C. bocki & C. komaii \\
\hline No. of statolites & $>2$ & $>2$ & $>4$ \\
\hline Size of body $(L \times W, m m)$ & $1-4 \times 0.5-3$ & $30 \times 15$ (extend $50-60)$ & $5-15 \times 2-8($ extend $10-18)$ \\
\hline Coloration & $\begin{array}{l}\text { Opaque with deep } \\
\text { scarlet star markings }\end{array}$ & Dark red to orange with stripes & Sea shell pink \\
\hline Dorsal papillae (No. shape) & None & 10-20, club & 5-6 pairs, digit \\
\hline Polar plates & Lobation & Lobation & Transversely elongate \\
\hline Gonads & Not observed & Summer-Autumn & July \\
\hline Hosts & Dendronephthya spp. & $\begin{array}{l}\text { Stereonephthya japonica, algae, } \\
\text { sea urchins, hydroids }\end{array}$ & Cladiella digitulata \\
\hline Depth & $26-32 \mathrm{~m}$ & Littoral & $14.7 \mathrm{~m}$ \\
\hline Localities & Munseom, Jejudo Is. Korea & Sagami Bay, Misaki, Tanabe, Japan & Sagami Bay, Japan \\
\hline References & Present study & Komai, 1920 & Utinomi, 1963 \\
\hline
\end{tabular}

above its periphery or lobation in living state (Fig. 1C-E). On its dorsal surface, any other dorsal papillae undeveloped in smaller and larger specimens. At its center, sense organ $(0.3 \times 0.4 \mathrm{~mm}$ in dia. $)$ with statocyst $(0.08 \times 0.08 \mathrm{~mm}$ in dia. $)$ 
in its middle part clearly seen under light microscope (Fig. 2C). Statolith forming two masses, each of which having more than 20 granules in its central position of cavity.

On oral side, mouth large, $0.4 \times 0.3 \mathrm{~mm}$ in dia., with many pharyngeal folds, opened at center of ventral side (Fig. 1F).

Histology. In most of both anatomical and histological respects, this new species is shown a similarity to $C$. bocki (see Komai, 1922) (Fig. 3).

Color. Milky white, semi-transparent, with lots of deep scarlet irregular star-shaped markings composed of red pigment cells on dorsal side (Fig. 1A, C-F). However, all of red markings are disappeared in formalin except for those on yellowish tentacle base (Fig. 1B).

Habitat. All specimens were attached commensally on the twigs and polyp masses of encrusting alcyonaceans, Dendronephthya spinulosa and other dendronephthyans inhabiting at 26-32 $\mathrm{m}$ deep of the same localities all year round since November, 2007. One to $18(7.2 \pm 4.5, n=25)$ individuals were aggregated on $10-25(16.1, \mathrm{n}=25) \mathrm{mm}$ long polyp masses (Fig. 1A, B).

Etymology. anthostella [Gr. anthos, flower; L. stella, star] is named for having lots of deep scarlet star-shaped markings on dorsal side.

Remarks. This species is distinguished from other Coeloplana ones such as C. bocki (see Komai, 1920, 1922, 1942, 1955) and C. komaii (see Utinomi, 1963) by its smaller size, no dorsal papillae, and the deep scarlet star-shaped markings on dorsal plane similar to host dendronephthyans in coloration (Table 1). We couldn't observe any unhatched cydippid embryos with eight comb rows from all specimens. Distribution. Korea (Jejudo Is.).

\section{ACKNOWLEDGEMENTS}

We are grateful to undergraduate student Hangeun Song for histological slide preparation. This research was a part of the Korean Coral Resources Bank (KCRB) program funded by the Ministry of Land, Transport and Maritime Affairs, Korea.

\section{REFERENCES}

Harbison, G. and L.P. Madin, 1982. Ctenophora. In: Synopsis and classification of living organisms (Ed., S.P. Parker). pp. 707-715. McGraw-Hill Book Co., New York.

Komai, T., 1920. Notes on Coeloplana bocki n. sp. and its development. Annot. Zool. Jap., 9: 575-584.

Komai, T., 1922. Studies on two aberrent ctenophores, Coeloplana and Gastrodes. Kyoto, Japan, pp. 1-102, pls. 1-9.

Komai, T., 1942. Lyrocteis and other resembled species (1) (2) (3). Anim. Plant, 10(1): 15-18; 10(2): 109-112; 10(3): 209216 (in Japanese).

Komai, T., 1955. General conception of Japanese Ctenophora. Bull. Biogeogr. Soc. Jap., 16-19: 13-14.

Mills, C.E., Internet since 1998. Phylum Ctenophora: list of all valid species names. Electronic internet document available at http://faculty. washington.edu/cemillis/Ctenolist.html. Published by the author. Web page established March 1998. frequently updated (see date at end of Web page).

Song, J.I. and S.J. Hwang, 2009. First record of a sessile Ctenophora, Lyrocteis imperatoris, and its embryos from Korea. Korean J. Syst. Zool., 25(3): 255-259.

Utinomi, H., 1963. Coeloplana komaii, a new creeping ctenophore from Sagami Bay. Jpn. J. Zool., 14(1): 15-19.

Received September 29, 2010 Accepted November 12, 2010 